\title{
Evaluation of the energy performance of Zero Energy residential Buildings: complexity of dynamic simulations and results variability
}

\author{
Silvia Di Turi ${ }^{1, *}$, Ilaria Falcone ${ }^{1}$, Iole Nardi $^{1}$, Laura Ronchetti $^{1}$ and Nicolandrea Calabrese ${ }^{1}$ \\ ${ }^{1}$ ENEA Italian National Agency for New Technologies, Energy and Sustainable Economic \\ Development of Engineering, DUEE Department, 00123 via Anguillarese 301 Santa Maria di Galeria \\ (Rome), Italy
}

\begin{abstract}
Due to its energy and environmental impact, the building sector has become a challenging field in order to fulfil the need for energy renovation and obtain low-consumption buildings. The main issue, for those who approach the feasible design of a Zero Energy Building (ZEB), is to assess, in the most realistic way possible, the thermal and energy needs and the energy production of the building, properly considering all the possible variables. Through the analysis of a newly built residential building case study, this work aims at showing the complexity of the ZEB design, analysing the energy performance as the design choices vary. After characterizing envelope and systems components, potential variations in the model are highlighted by applying a set of updated climatic data, varying occupancy, shading systems and natural ventilation functioning, often neglected. It leads to a wide and differentiated range of results, consequently influenced by the design phase. The work aims at providing, in the definition of the energy performance of the building, an evaluation of the variations obtained from the variables analysed that in the modelling phase are normally considered as a boundary but which instead play a key role for achieving the ZEB objective.
\end{abstract}

\section{Introduction}

The reduction of resource consumption, often promoted via Institutional suggestions and National goals, is permeating our daily activities [1].

Indeed, in this sense, huge efforts are ongoing also for the building sector, which in 2019 was responsible of about 128 EJ of final energy use consumption [2] and which is clearly experiencing a shift towards "zero energy buildings" (ZEBs) by promoting a pathway passing through "nearly zero energy buildings" (nZEB) (for example by imposing that newly built building must be nZEB).

The definition of the latter kind of buildings is provided by the EPBD itself [3] as "a building that has a very high energy performance, as determined in accordance with Annex I. The nearly zero or very low amount of energy required should be covered to a very

\footnotetext{
${ }^{*}$ Corresponding author: silvia.dituri@enea.it
} 
significant extent by energy from renewable sources, including energy from renewable sources produced on-site or nearby".

Nevertheless, several metrics (i.e., for the site energy or source energy), or different balance boundaries (i.e. with respect to renewable supply/generation sites) as well as different normalization (i.e. net floor, gross volume, etc) have led to the spread of different definitions of ZEB [4; 5]. Add to this, in Europe, each Member State had to adopt the definition by adapting the Directive to its Regional laws. This complex framework did not help to clarify some turn points of ZEBs design, which indeed are becoming clear by experience, a that are ever included in both grey and white literature. Abundance of definitions [6-8] is fortunately coupled with success studies [7].

Of course, given the ZEB definition, for its design powerful dynamic evaluation tools should be employed, since detailed results are provided. The more accurate the results, the higher the number of variables and settings to be defined, the greater the computational cost.

In this sense, the EnergyPlus engine is one of the most employed from academics and to trained designer whose choices become even more relevant when realizing low-consuming buildings, also for its accuracy and flexibility [9].

An interesting approach to building simulation has been proposed in [10], where a residential settlement of $18000 \mathrm{~m}^{3}$ of net volume equipped with efficient envelope and plants has been modelled. Results prove the technical-economic feasibility of the case study (which was under construction at the time of publishing) and whose cost was estimated of $1780 € / \mathrm{m}^{2}$ (for apartments with independent domestic PV plant) and $1700 € / \mathrm{m}^{2}$ for other flats, slightly higher than an average new building $\left(1400 € / \mathrm{m}^{2}\right)$

In addition, the optimization of the design and functioning phases is crucial [11], as a ZEB requires facing some challenges in terms of passive design strategies, energy efficient technologies and energy generation.

In [12], it was used to benchmark residential building in Brunei according to three types of houses, providing yearly energy use intensity (EUI) ranging from approximately 64.2 to $47.8 \mathrm{kWh} / \mathrm{m}^{2}$. The paper, which takes into account electrical load, occupancy schedule, lighting profile, appliances and so on, provides the energy saving potentials taking into account geometry, orientation and shading conditions.

In a recent work [13], a purposely conceived tool that couples EnergyPlus and Matlab (and called EMAR) is presented. This tool requires 63 numerical inputs (that is, less than a simple EnergyPlus model) to create simplified (but accurate) building models: three different buildings were modelled for this aim, showing the heating and cooling load, the thermal energy demand and primary energy consumption.

In this work, Design Builder coupled with EnergyPlus was employed to show the complexity of the ZEB design, by taking as reference a newly built residential case study, and by showing the opportunities for improving energy performance as the design choices vary. A proper design should carefully evaluate, select and adopt: (i) performing envelope and systems components; (ii) updated climatic data; (iii) reliable occupancy and using profiles; (iv) shading systems functioning; (v) natural ventilation. Variations of these parameters in the model can cause a range of results that they imply, consequently influencing the design phase.

The work aims, specifically, at providing elements to evaluate the relevance, in the definition of the energy performance of the building, of some of the variables that in the modelling phase are normally considered as a boundary, but which instead play a role in advanced energy design, providing an evaluation of the variations obtained from the several scenarios analysed, necessary in the design phase for achieving the ZEB objective.

This work is structured as follows: in section 2, the methodology is described; in section 3 , the reference case study is presented, as well as the parametric variability; results are shown and discussed in section 4; finally, conclusions are drawn. 


\section{Methodology}

In the design of a zero-energy residential building, the first difficulty to be faced is represented by the determination, in the most realistic way, of the thermal and energy needs and the energy production of the building itself, properly considering all the possible variables contributing to its determination. In this sense, modelling tools available today, capable of performing dynamic simulations, allow to acquire a greater awareness of the building and of systems detailed behaviour, taking into account, in addition to the temporal variability of the properties, multiple aspects concerning the characterization of envelope and systems components, the regulation and operating profiles, the occupancy and using profiles, aspects that contribute to the definition of the building in relation to indoor microclimatic and external climatic conditions. Powerful dynamic simulation tools, which provide very detailed output, require an equally significant variety of input data, the definition of which can deeply affect the final results. In fact, each of the parameters adopted substantially affects the performance of the building itself, and the choices made result in a range of highly variable and conditioned outputs. This outlines the importance of critically analysing each of the input data chosen underlines the evident imperative in evaluating the choices to be made in an exhaustive manner. To better assess the effects (in the definition of the building energy performance) of some of the variables that are normally considered as a boundary in the modelling phase (which instead play a role in advanced energy design), it was decided to analyse a newly built residential building, dynamically simulating its energy performance, as the operating profiles, the occupancy and using profiles vary. The analysed case study is a benchmark building, purposely conceived following some good-practices in building construction and bio-climatic architecture. Moreover, consolidated technologies for building envelope components and plant systems were considered in the building design choices.

Specifically, the reference configuration (hereinafter Ref_case) has been defined and customized in relation to the definition of occupancy profiles, use profiles and activities. The results of the dynamic simulation are conducted on monthly and annual basis for the case study under examination in climatic zone D (city of Rome).

The climatic file was built according to the updated climatic data available from Italian Termotechnical Committee and is the basis for the analysis of the results related to the Ref_case. Some considerations follow this analysis about the possible use of different climatic file (such as the EnergyPlus weather file), considering its influence on the energy simulation results in the so-called EP_case.

Then, the functioning profiles and schedules related to occupancy, ventilation and shading systems were modified, considering for each aspect a maximum and a minimum configuration, to be compared with the reference case with customized/tailored profiles.

At the end, a discussion of the results is made in order to define their variation in assessing the energy performance of a ZEB and show the complexity of design.

\section{The case study}

Building geometry and constructive characteristics, as far as the characteristics of the HVAC and DHW systems, are common to all the analysed configurations and are detailed in the following. A multi-storey building model was conceived as representative as possible of the current real estate market, but at the same time it was conceived as highly performing, according to the definition of ZEB [4]. For this purpose, an intensive preliminary work was carried out to select and analyse the characteristics of the model, under all the constructive, plant, bioclimatic and use profiles aspects, which combine to create the complex buildingplant system, in order to obtain an optimization of passive and active strategies, and energy production from renewable sources. A 5-storey linear development building with 13 
residential units was therefore chosen. The apartments are distributed in number of two or three per floor and are between 50 and $85 \mathrm{~m}^{2}$ in size, up to a maximum of $113 \mathrm{~m}^{2}$ (Figure 1).
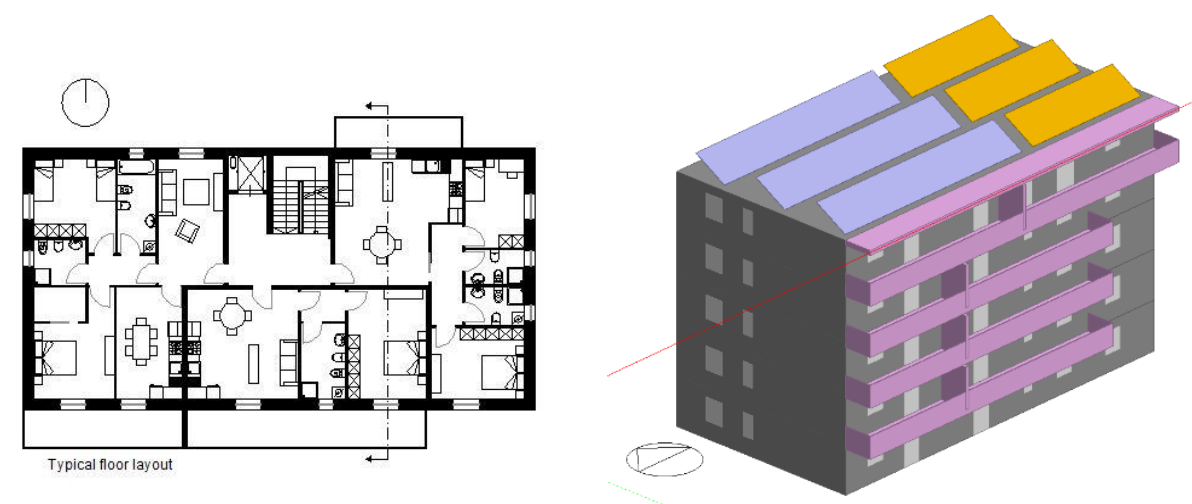

Fig. 1. Layout of the typical floor and related functional distribution.

The analysis was carried out in climatic zone $\mathrm{D}$, taking as reference the city of Rome characterized by 1415 Degree Days. Given the obsolescence of the climatic data in the software, new ones were used, starting from the latest climatic parameters made available by the Italian Thermotechnical Committee. The building develops along the east-west direction, that is, with the main façades to the South and North. It was chosen because the thermal gain during the winter season is optimal in the South, even if the North facade is more exposed to heat loss through the envelope and has a reduced gain from solar radiation. In summer, on the other hand, the south facade receives less direct radiation than the east and west ones, as the sun at noon has a higher position and the inclination of the sun's rays tends to be perpendicular to the earth's surface. Thus, the prevailing orientation to North and South is a better condition, because, on the contrary, it is very difficult to control quite horizontal solar rays also with solar device in East and West facades. The adopted solution allows a good compromise in solar gains during the year. The fixed shading systems, such as loggias and balconies, have been designed both taking into account the solar exposure and calculating the projection depths according to the solar inclination and the hypothesized internal distribution, placing the larger loggias at the service of the living area. Additional shading systems (dynamic and equipped with control and adaptive systems depending on the temperatures and the inclination of the sun's rays) are provided on all openings, with particular attention to the South, East and West façades.

As for the building envelope, its definition took into account the minimum requirements that each component must fulfil in order to meet current regulatory standards with respect to the reference building [14].

The choice to rely on these limits is useful as it helps to understand if, by now, it is possible to reach high standards in the direction of ZEB. Specifically, the building model envisages a reinforced concrete framed structure with highly insulated walls. For the vertical walls, it was decided to use rectified porous brick, $30 \mathrm{~cm}$ thick, associated with $7 \mathrm{~cm}$ of rock wool insulation $(\lambda=0.034 \mathrm{~W} / \mathrm{mK})$ obtaining an overall transmittance value $\mathrm{U}=0.280$ $\mathrm{W} / \mathrm{m}^{2} \mathrm{~K}$. For the ceiling, a flat roof insulated with $8 \mathrm{~cm}$ of rock wool was chosen, characterized by a transmittance of $0.23 \mathrm{~W} / \mathrm{m}^{2} \mathrm{~K}$.

The intermediate floors are made of brick-cement, with a layer of thermal and acoustic insulation. Openings have been defined based on the characteristics of the most performing windows currently available on the market, always respecting the minimum standards of the DM 26.6.2015 [14] i.e a high performance double glazed PVC window (4-12-4) with Uw 
$=1,8 \mathrm{~W} / \mathrm{m}^{2} \mathrm{~K}$. It was decided to implement centralized systems for both air conditioning and domestic hot water.

Autonomous and independent management systems are provided inside the accommodation through the installation of room chrono-thermostats. Three air-to-water heat pumps are used for both heating and cooling. The heat pumps have been sized by evaluating the thermal needs and calculating the power required in heating and cooling for the modelled building. A set point temperature of $20^{\circ} \mathrm{C}$ in winter and $26^{\circ} \mathrm{C}$ in summer with a tolerance of $2{ }^{\circ} \mathrm{C}$ has been fixed for all the apartments. Table 1 shows the main characteristics of the heating and cooling heat pumps.

Table 1.Heating and cooling heat pumps system characteristics

\begin{tabular}{|c|c|c|c|c|c|}
\hline \multicolumn{7}{|c|}{ Heating cooling -DHW heat pumps systems } \\
\hline \multicolumn{2}{|c|}{ Heating } & \multicolumn{2}{c|}{ Cooling } & \multicolumn{2}{c|}{ DHW } \\
\hline $\begin{array}{c}\text { Heating } \\
\text { capacity }\end{array}$ & $\begin{array}{c}14 \mathrm{~kW} \\
(\mathrm{x} 3 \mathrm{~h} . \mathrm{p} .)\end{array}$ & $\begin{array}{c}\text { Cooling } \\
\text { capacity }\end{array}$ & $\begin{array}{c}13 \mathrm{~kW} \\
(\mathrm{x} 3 \mathrm{~h} . \mathrm{p} .)\end{array}$ & $\begin{array}{c}\text { Heating } \\
\text { capacity }\end{array}$ & $90 \mathrm{~kW}$ \\
\hline $\begin{array}{c}\text { Power } \\
\text { consumption }\end{array}$ & $\begin{array}{c}4,36 \mathrm{~kW} \\
(\mathrm{x} 3 \text { h.p. })\end{array}$ & $\begin{array}{c}\text { Power } \\
\text { consumption }\end{array}$ & $\begin{array}{c}4,47 \mathrm{~kW} \\
(\mathrm{x} 3 \text { h.p. })\end{array}$ & $\begin{array}{c}\text { Power } \\
\text { consumption }\end{array}$ & $24 \mathrm{~kW}$ \\
\cline { 1 - 3 } COP & 3,21 & EER & 2,91 & COP & 3,70 \\
\hline T delivery & $45^{\circ} \mathrm{C}$ & T delivery & $7^{\circ} \mathrm{C}$ & \multirow{2}{*}{ T delivery } & $62^{\circ} \mathrm{C}$ \\
\hline T return & $40^{\circ} \mathrm{C}$ & T return & $12^{\circ} \mathrm{C}$ & & \\
\hline
\end{tabular}

For the production of domestic hot water, on the other hand, a dedicated heat pump system integrated with solar thermal and storage tank has been provided. To meet the need for domestic hot water and at the same time ensure integrated production from renewable sources, the installation of vacuum tube solar collectors was planned, with an absorbing surface of about $36 \mathrm{~m}^{2}$ and a gross surface of about $57 \mathrm{~m}^{2}$ and three storage tanks of 1000 litres each. Moreover, monocrystalline photovoltaic panels with a nominal power of $370 \mathrm{~W}$ were installed on the roof over a total area of $93.6 \mathrm{~m}^{2}$.

\subsection{The reference case study}

Since occupation and use significantly affect results, it is essential to hypothesize "realistic" user behaviour and consequently a consistent use of plant systems. A maximum presence of the total number of occupants was assumed for evening and night hours, while it was decided to consider a minimum presence during the day, consistent with working or school hours. The occupancy density in the reference case study was assumed ranging to be equal to 0.044 people $/ \mathrm{m}^{2}$ on average with a metabolic factor of 0.90 . Consistent with the occupation, the profile of use of domestic hot water provides for a higher consumption during the early hours of the morning and during the hours of the late afternoon/evening, when the inhabitants return to their residence, with a consumption rate of $3.11 \mathrm{l} / \mathrm{m}^{2}$ per day.

Tailored occupancy, ventilation and shading schedules, DHW schedule, and environmental control schedule are shown below in Figure 2. The y-axis of the graph in fig. 2a returns the value 0 if the system is OFF, the value 1 if it is $\mathrm{ON}$ and intermediate values to indicate that the equipment is controlled using the main or the setback temperature set-point data (in the case of values greater than 0.5 of between 0 and 0.5 respectively). For the Fig. $2 b$ the values indicate the fraction of usage: i.e., for the occupancy the value 0 stands for the unoccupied building and 1 for the fully occupied building. Similarly, when the shading and ventilation profiles are set on 1 , the shading system is active, and windows are all opened. If they are set on 0 the shading system is unavailable, and windows are closed. 


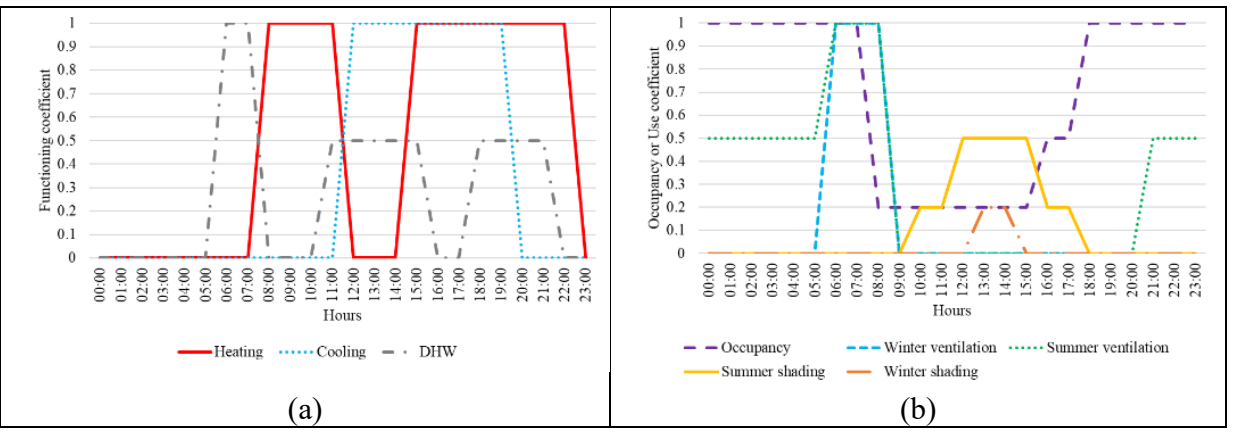

Fig. 2. Heating, Cooling and Domestic Hot Water schedules (a) and Occupancy, Ventilation and Shading profiles (b).

\subsection{Parametric variability of significant parameters}

In order to highlight the extreme variability of energy dynamic simulations results for a highefficient insulated building and to demonstrate how difficult is to determine that it is a Zero Energy Buildings through dynamic simulations, a variation of significant parameters was carried out during simulation process. For this reason, the functioning for heating, cooling and DHW systems was left unchanged respect to the Reference case study, while the schedules related to occupancy, ventilation and shading systems were modified, considering for each aspect a maximum and a minimum profile, to be compared with the reference case with customized/tailored profiles.

To have the highest range of variation, the modelling was stressed. The occupancy minimum profile was set up equal to 0.5 from 6 p.m. to 8 a.m. and 0.2 for the other hours of the day, while the maximum was fixed to a full occupancy rate, equal to 1 . Shading schedules were set equal to 0 for the minimum and to 1 for the maximum, for all the days of the year. However, in each profile set up for shading systems, the solar control has been left active. In the case of natural ventilation, a detailed profile for each configuration was imposed in order to guarantee a minimum air change rate during winter and the maximum free cooling during summer. 


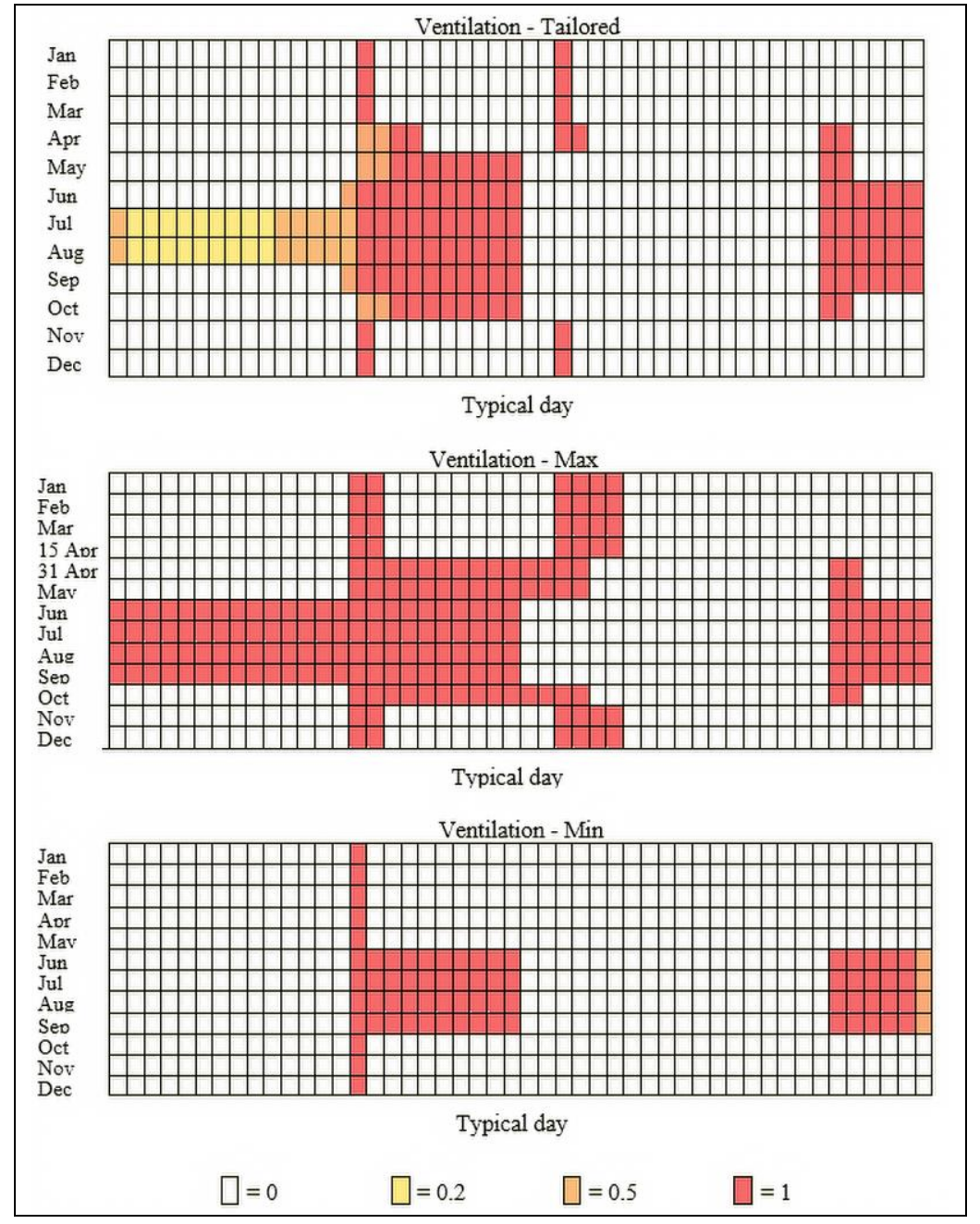

Fig. 3. Typical days schedule of ventilation for each month in tailored, maximum and minimum configuration. Each square corresponds to half an hour.

The chosen detailed schedules are shown in Figure 3 and vary in the different seasons, according to a typical day profile. Each square in the figure corresponds to half an hour of the day and each color to a fraction of functioning value for ventilation. Its working is compatible with the heating and cooling functioning in order to avoid overlaps and to not compromise the efficiency of the adopted conditioning systems.

Finally, each case study was varied adopting the configurations illustrated in the Table 2.

Table 2. Case study summary and related schedules for the varied parameters $(\mathrm{O}=$ Occupancy; $\mathrm{S}=$ shading, $\mathrm{V}=$ Ventilation).

\begin{tabular}{|c|c|c|c|c|c|c|c|c|c|}
\hline Case study & Ref & Omax & Omin & Smax & Smin & Vmax & Vmin & Max & Min \\
\hline Occupancy & Tailored & Max & Min & Tailored & Tailored & Tailored & Tailored & Max & Min \\
\hline $\begin{array}{c}\text { Shading } \\
\text { system }\end{array}$ & Tailored & Tailored & Tailored & Max & Min & Tailored & Tailored & Max & Min \\
\hline Ventilation & Tailored & Tailored & Tailored & Tailored & Tailored & Max & Min & Max & Min \\
\hline
\end{tabular}




\section{Results and discussion}

\subsection{The reference case study results}

From the analysis of the output deriving from simulation, it was possible to obtain the results in aggregate form regarding the thermal and energy needs of the building and some considerations on the efficiency of the implemented systems, allowing to compare the performances obtained by the different configurations analysed, and to estimate the incidence of the correct identification of parameters, such as occupancy rate and operating profiles.

The first step towards determining the energy performance of the reference building (Ref_case) and verifying the ZEB objective is certainly the evaluation and analysis of the thermal needs, which will consequently determine the energy consumption of the building. The main contributions divided by macro categories (envelope, ventilation, solar gains and occupancy) and the overall balance of the building were considered, determining its behaviour both during winter and during summer. The Ref_case has been analysed through annual EnergyPlus/DesignBuilder simulation based on climatic file with the data of the Italian Termotechnical Committee.

The thermal balance was calculated during the standard winter period for the climatic zone $\mathrm{D}$, in which Rome is located, from the $1^{\text {st }}$ November to $15^{\text {th }}$ April, while the summer period was fixed by the author from the $1^{\text {st }}$ June to the end of September.

As shown in Fig. 4, the winter thermal energy need, calculated from November 1 to April 15 and obtained considering the four main contributes (envelope components behaviour, ventilation, occupancy and solar gains), is equal to $6.36 \mathrm{kWh} / \mathrm{m}^{2}$ while the summer requirement is equal to $6.34 \mathrm{kWh} / \mathrm{m}^{2}$.

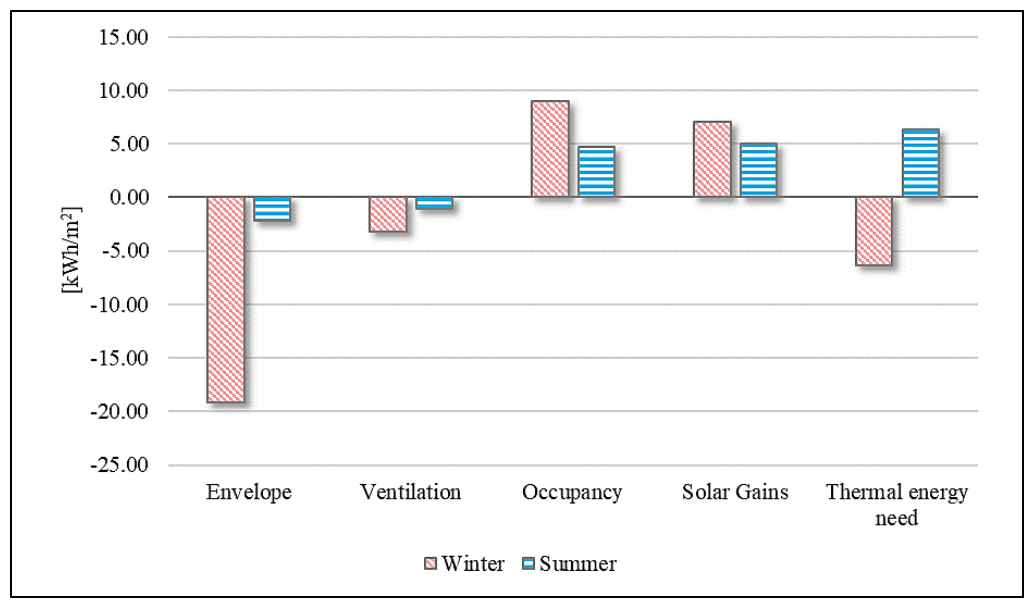

Fig. 4. Winter and summer thermal energy need for the Ref_case

The analysis of the output results deriving from the simulations also made it possible to obtain the thermal energy needs for each service analysed (heating, cooling, domestic hot water) and electricity consumption as shown in Table 3 . Results are obviously influenced by the performance of plant systems, defined in detailed in the HVAC module. 
Table 3. Thermal and electric energy for heating, cooling and DHW [kWh] and PV electricity production.

\begin{tabular}{|c|c|c|c|c|c|c|c|c|}
\hline & \multicolumn{2}{|c|}{ Heating } & \multicolumn{2}{c|}{ Cooling } & \multicolumn{3}{c|}{ DHW } & PV \\
\cline { 2 - 9 } Month & $\begin{array}{c}\text { Thermal } \\
\text { energy }\end{array}$ & $\begin{array}{c}\text { Electric } \\
\text { energy }\end{array}$ & $\begin{array}{c}\text { Thermal } \\
\text { energy }\end{array}$ & $\begin{array}{c}\text { Electric } \\
\text { energy }\end{array}$ & $\begin{array}{c}\text { Thermal } \\
\text { energy } \\
\text { (heat pump } \\
\text { + solar) }\end{array}$ & $\begin{array}{c}\text { Coverage } \\
\text { by solar } \\
\text { collectors } \\
(\%)\end{array}$ & $\begin{array}{c}\text { Electric } \\
\text { energy } \\
\text { (heat } \\
\text { pump) }\end{array}$ & $\begin{array}{c}\text { Electri- } \\
\text { city pro- } \\
\text { duction }\end{array}$ \\
\hline Jan. & 1515 & 486 & 0 & 0 & 4534 & $29 \%$ & 899 & 1537 \\
\hline Feb. & 842 & 270 & 0 & 0 & 4633 & $35 \%$ & 846 & 1819 \\
\hline Mar. & 491 & 157 & 0 & 0 & 4816 & $53 \%$ & 636 & 2358 \\
\hline Apr. & 43 & 13 & 0 & 0 & 3862 & $73 \%$ & 303 & 2671 \\
\hline May & 0 & 0 & 0 & 0 & 4130 & $75 \%$ & 301 & 3028 \\
\hline June & 0 & 0 & 1626 & 1285 & 4070 & $84 \%$ & 185 & 3052 \\
\hline July & 0 & 0 & 3103 & 1336 & 4142 & $96 \%$ & 47 & 3320 \\
\hline Aug. & 0 & 0 & 2985 & 1362 & 3736 & $94 \%$ & 70 & 3173 \\
\hline Sep. & 0 & 0 & 1115 & 850 & 3587 & $79 \%$ & 223 & 2601 \\
\hline Oct. & 0 & 0 & 0 & 0 & 3585 & $65 \%$ & 363 & 2206 \\
\hline Nov. & 198 & 63 & 0 & 0 & 4216 & $36 \%$ & 755 & 1652 \\
\hline Dec. & 904 & 290 & 0 & 0 & 5214 & $27 \%$ & 1060 & 1526 \\
\hline Year & 3992 & 1280 & 8829 & 4832 & 50526 & $62 \%$ & 5688 & 28942 \\
\hline
\end{tabular}

Comparison of electricity needs $[\mathrm{kWh}]$ and production from renewable sources for the Ref_case is shown in Fig. 5. The greatest electric energy consumption regards the cooling demand, while in winter, the electricity required is high especially in January, February and December. The coverage of thermal energy need from the solar thermal collectors for DHW, reaches the highest value during July and August (96\% and 94\%), while ranges from $29 \%$ to $53 \%$ during the winter period. The electricity production by the photovoltaic system, however, reveals that for each month there is the total coverage of the electric requirement and a surplus production, guaranteeing the achievement of the Positive Energy Building (beyond the Zero energy target).

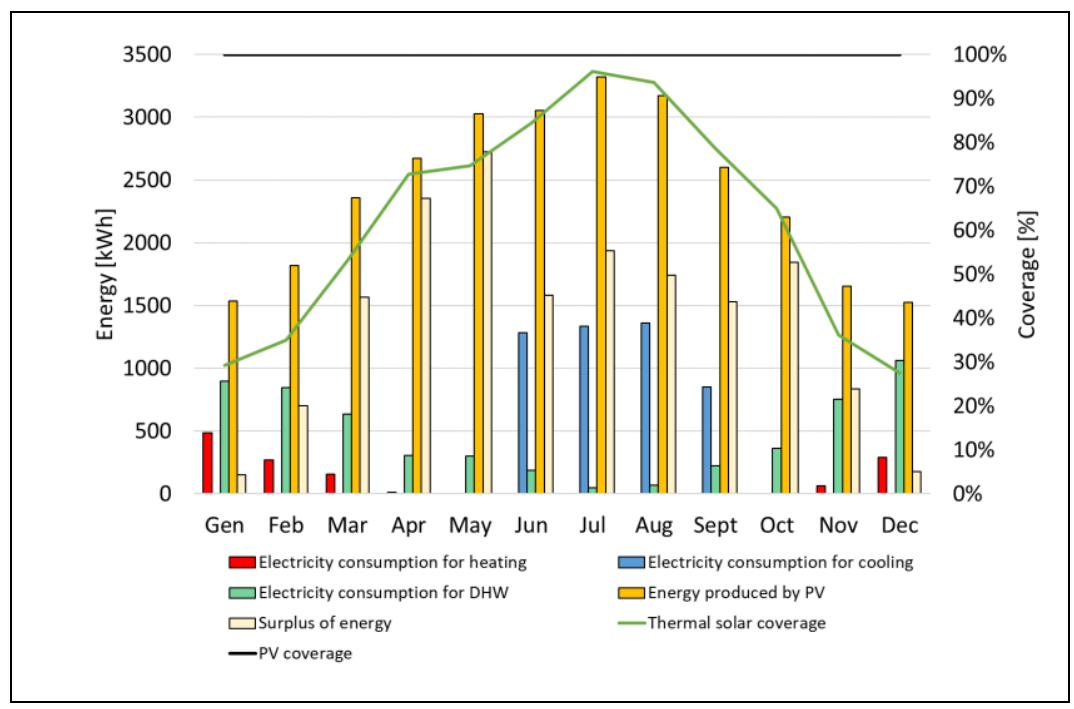

Fig. 5 Ref_case - Comparison of electricity needs and production from renewable sources.

The achieved results give the possibility to compare them with the other cases in order to assess the variability of the results, depending on single different parameters. 


\subsection{The influence of climatic data on the simulations}

Results from the reference building were then the basis for further considerations on parameters variation.

The first issue is related to the climatic data available for the energy simulation.

For this reason, before analysing each variation, the model was simulated with the EnergyPlus weather data (EP_case), in order to compare the results with the Ref_case (based on CTI data).

The wide differences between temperatures in the two climatic files is evident by the following graph (Fig. 6). The maximum difference between the temperatures is achieved in June (up to $10^{\circ} \mathrm{C}$ ). The minimum average monthly deviation of temperatures is recorded in February $\left(0.6^{\circ} \mathrm{C}\right)$, while the maximum one occurs during the month of August with $3.25^{\circ} \mathrm{C}$.

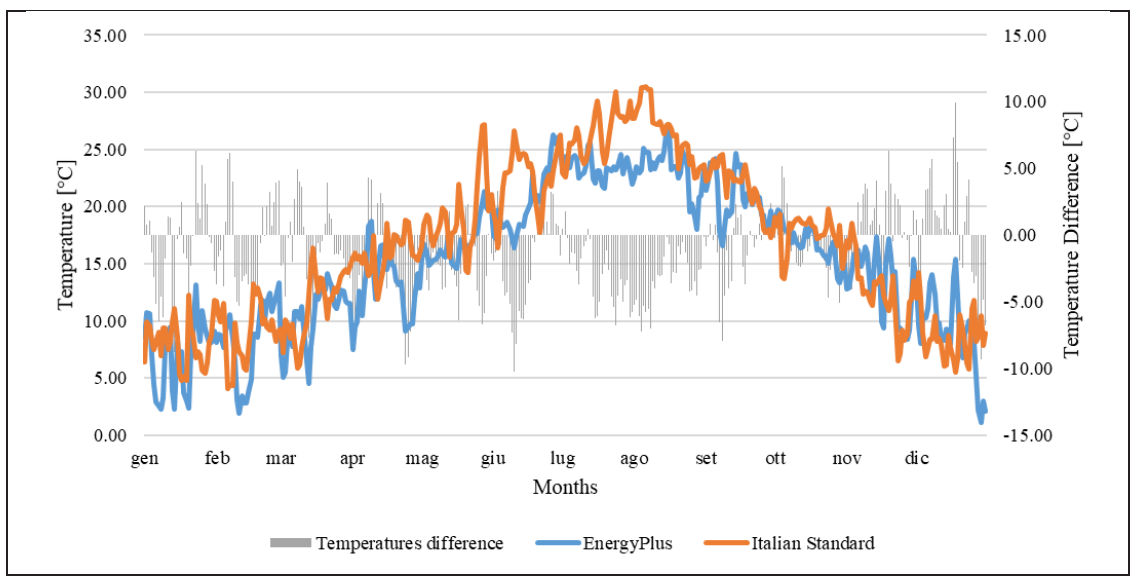

Fig. 6. Trends of temperature in the different climatic files (EnergyPlus and Italian CTI) and differences in ${ }^{\circ} \mathrm{C}$.

Considering only the contributes of envelope, solar gains, occupancy and ventilation (Fig.7), the total thermal energy need goes from $6.36 \mathrm{kWh} / \mathrm{m}^{2}$ in the reference case to 6.87 $\mathrm{kWh} / \mathrm{m}^{2}$ in the EnergyPlus case in winter, while it varies from $6.34 \mathrm{kWh} / \mathrm{m}^{2}$ in the Ref_case to $2.85 \mathrm{kWh} / \mathrm{m}^{2}$ in the EP_case in summer. It is evident that the greatest difference is found during summer regime, due to the different behaviour of the envelope components and different solar gains.

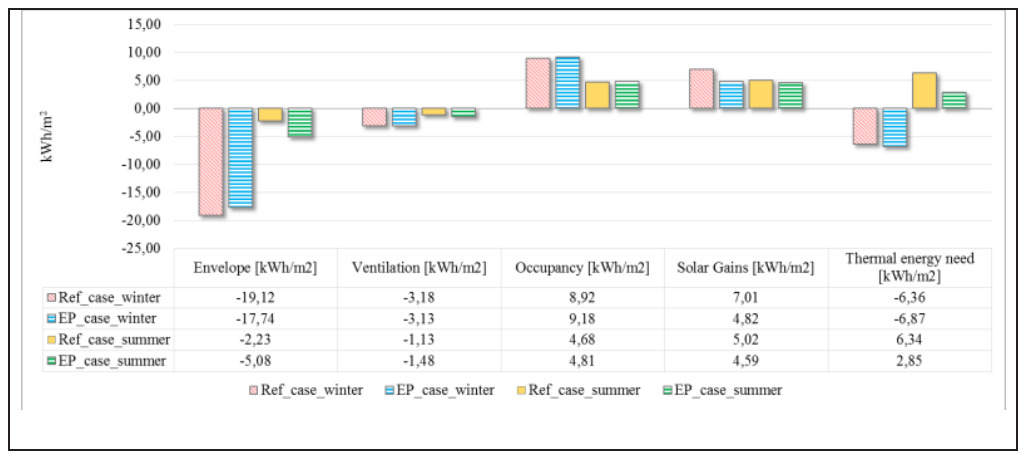

Fig. 7. Different contributions to thermal energy requirement in winter and summer for Ref_case and EP_case. 
These differences cause a great divergence in terms of heating and cooling thermal energy demand and electric energy consumption.

The thermal energy demand (Fig. 8) varies for heating and cooling. Annually, the Ref_case needs a thermal energy amount of $40 \%$ less than EP_case for heating, while the contrary occurs in summer when EP_case requires $49 \%$ of thermal energy less than EP_ref. Regarding the Domestic Hot Water, the thermal energy demand by heat pump of Ref_case is $12 \%$ below the EP_case demand, annually. This is due to the different production of thermal energy by the solar collectors in EP_case that produce $5967 \mathrm{kWh}$ less than Ref_case, annually. Thus, the latter has an annual production of $12 \%$ more than the EP_case. Moreover, in the EP_case, solar collectors are not sufficient to reach the total coverage of DHW demand also in the hot months of July and August, due to different radiation values of climatic files. Annually the Ref_case and EP_case reach a coverage of $62 \%$ and $51 \%$ for the energy production for $\mathrm{DHW}$ respectively.

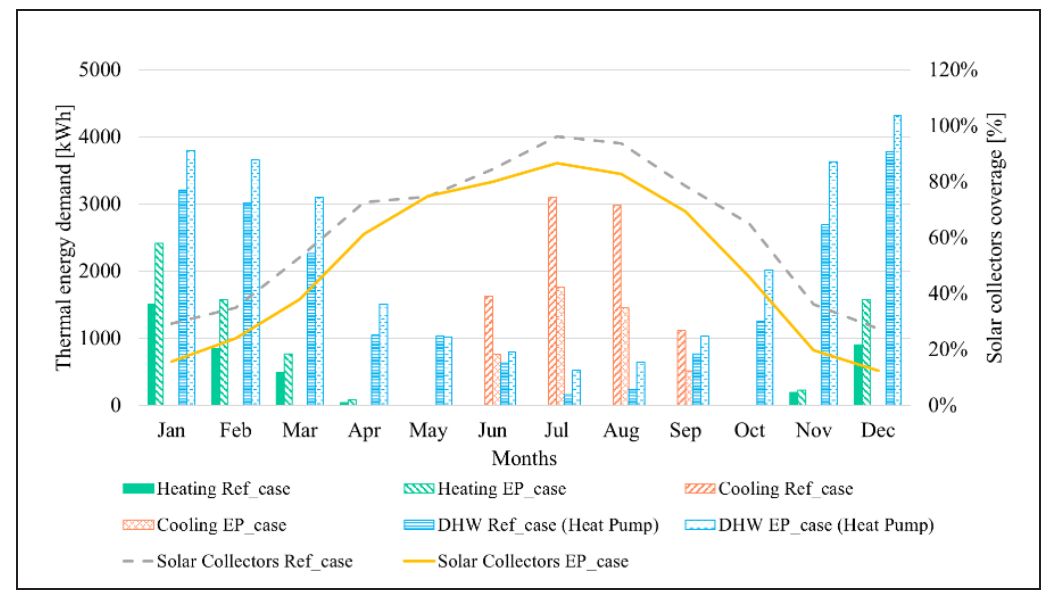

Fig. 8. Monthly thermal energy need (kWh) and coverage by solar collector production (\%) for Ref_case and EP_case.

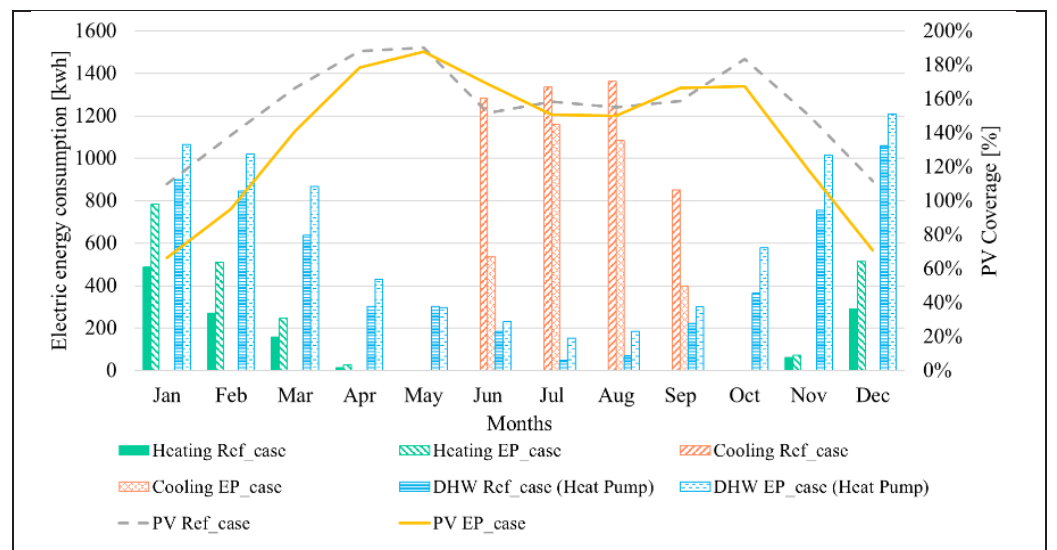

Fig. 9. Monthly electric energy consumption (kWh) and Photovoltaic coverage of electricity need (\%) for Ref_case and EP_case.

Regarding the electricity consumption (Fig. 9), the EP_case has generally higher electricity consumption in winter months and lower in summer months, coherently with the 
thermal energy need results. The obtained data for electricity consumptions are influenced by the performance of plant systems, set as described in section 3 .

Annually, the Ref_case shows an electricity energy saving of $41 \%$ for heating respect to the EP_case, while the contrary occurs for cooling (the EP_case registers an energy saving of $34 \%$ respect to the Ref_case). The DHW production is $23 \%$ more in EP_case respect to Ref_case and the PV energy production of EP_case is 29\% less than in Ref_case.

Another important difference is the monthly coverage of the electric energy demand by renewable sources that is the starting point to consider the case study a Zero Energy Building. While the Ref_case has a coverage beyond the $100 \%$ in all the months, the EP_case shows some criticalities in the winter months, especially in January and December, when the PV electricity production reaches $66 \%$ and $71 \%$ of the total needs. Although this, the annual PV production covers the $155 \%$ and $138 \%$ of the total annual electric energy need, making both the case-studies positive buildings.

\subsection{Parametric analysis: ventilation, occupancy and shading system functioning variation results}

The variation of the ventilation, occupancy and shading system functioning gives many possibilities of thinking about the crucial aspects in the assessment of a Zero Energy Building during the preliminary design.

In these cases, it is necessary to start by thermal need differences (considering only the contribution of envelope, occupancy, ventilation and solar gains), shown in the fig. 10 and 11. Each varied profile determines a deviation for the macro-categories identified.

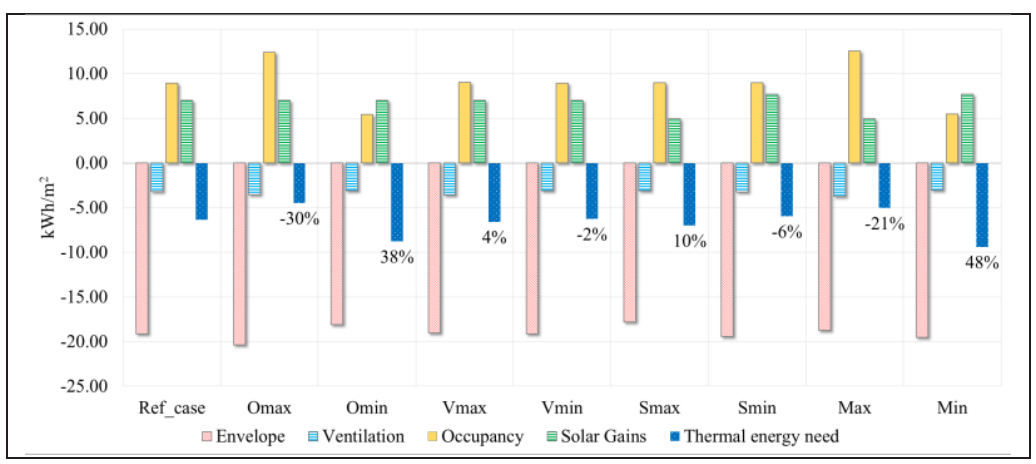

Fig. 10. Normalized thermal requirement for winter in the analysed cases (contributions of envelope, ventilation, occupancy and solar gains and total amount) in $\mathrm{kWh} / \mathrm{m}^{2}$.

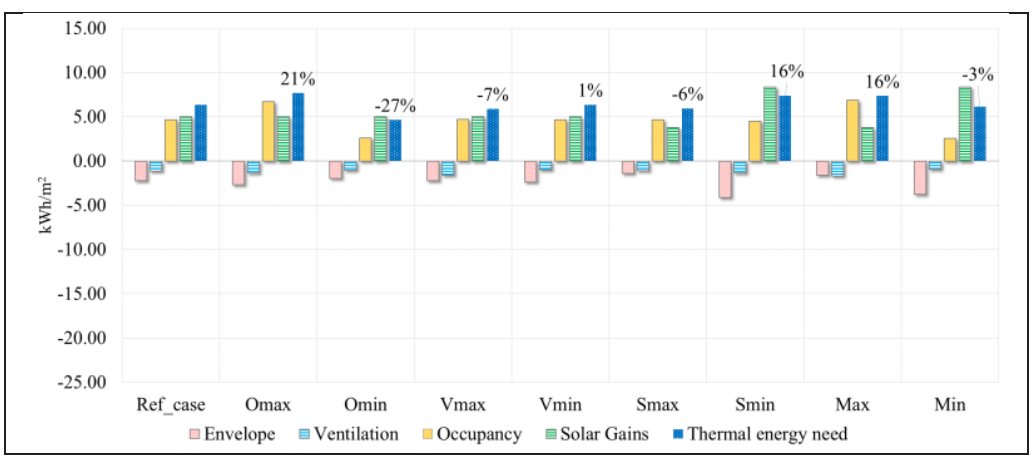

Fig. 11. Normalized thermal requirement for summer in the analysed cases (contributions of envelope, ventilation, occupancy and solar gains and total amount) in $\mathrm{kWh} / \mathrm{m}^{2}$. 
In the cases Omax and Omin, occupancy contributions also affect the dispersions of the envelope, due to the different indoor temperatures. The maximum occupancy determines a decrease of $30 \%$ in the thermal winter requirement and an increase of $21 \%$ in summer requirement. The thermal energy need varies from $6.36 \mathrm{kWh} / \mathrm{m}^{2}$ (Ref_case) to $4.47 \mathrm{kWh} / \mathrm{m}^{2}$ (Omax) for heating, and from $6.34 \mathrm{kWh} / \mathrm{m}^{2}$ to $7.69 \mathrm{kWh} / \mathrm{m}^{2}$ for cooling. The minimum occupancy, instead, causes an increase up to $38 \%$ in winter (the thermal energy need of the Omin case is of $8.77 \mathrm{kWh} / \mathrm{m}^{2}$ ) and a decrease of $27 \%$ in summer (the thermal energy need of the Omin case is of $4.65 \mathrm{kWh} / \mathrm{m}^{2}$ ). In the case of natural ventilation variation, generally it does not influence in such relevant way as expected. The thermal need ranges from 6.26 $\mathrm{kWh} / \mathrm{m}^{2}(-2 \%)$ to $6.58 \mathrm{kWh} / \mathrm{m}^{2}(+4 \%)$ for Vmin and Vmax respectively, while in summer it decreases of $7 \%$ for $\operatorname{Vmax}\left(5.91 \mathrm{kWh} / \mathrm{m}^{2}\right)$ and increases of $1 \%$ for $V \min \left(6.38 \mathrm{kWh} / \mathrm{m}^{2}\right)$. In addition, the changing of shading system profiles is not as relevant as occupancy, but their influence is greater than the natural ventilation profile. In fact, the Smax case determines a winter thermal need increase of $10 \%\left(6.99 \mathrm{kWh} / \mathrm{m}^{2}\right)$ and a summer thermal requirement decrease of $6 \%\left(5.97 \mathrm{kWh} / \mathrm{m}^{2}\right)$. For Smin these values are respectively $-6 \%\left(6.99 \mathrm{kWh} / \mathrm{m}^{2}\right)$ and $+16 \%\left(5.97 \mathrm{kWh} / \mathrm{m}^{2}\right)$, due to the increase of solar gains contribution in winter and their decrease in summer.

Finally, the extreme cases, the Max and Min cases, derived from the combination of maximum and minimum profiles, demonstrate that the results could vary from $5.05 \mathrm{kWh} / \mathrm{m}^{2}$ $(-21 \%)$ to $9.39 \mathrm{kWh} / \mathrm{m}^{2}(+48 \%)$ for winter thermal need and from $7.36 \mathrm{kWh} / \mathrm{m}^{2}(+16 \%)$ to $6.17 \mathrm{kWh} / \mathrm{m}^{2}(-3 \%)$ for summer thermal need respectively. For the Max case, solar gains are extremely reduced in winter (increasing the shading functioning), as well as the occupancy rises, determining a decrease in winter thermal requirement. In summer, these same contributions determine the rise of thermal need, but with a minor percentage variation. The same principles occur in the Min case with opposite results (minimum shading and occupation profiles).

Considering the HVAC systems use and the electric energy consumptions in the analysed cases, it is possible to derive some interesting outputs. The DHW energy consumption is equal for all the analysed cases, as well as the coverage by solar collectors for DHW production (about $63 \%$ in the year), because of the use of the equal schedules and climatic data. Thus, for the following analysis they are not considered, except for the total balance.

The maximum electric energy consumption is recorded for cooling in the months from July to August (Fig.12). In the configurations Omax and Smin the consumptions in July reach $1368.34 \mathrm{kWh}$ and $1375.09 \mathrm{kWh}$ respectively. In August, the electricity consumptions vary from the minimum value of $1354.25 \mathrm{kWh}$ for the Omin to the maximum value of 1367.12 kWh for Omax.

In winter, the worst configuration is the Min case in the month of January with 959.91 $\mathrm{kWh}$ of electric consumption, while the best performance is achieved by Omax configuration (264.31 kWh). 


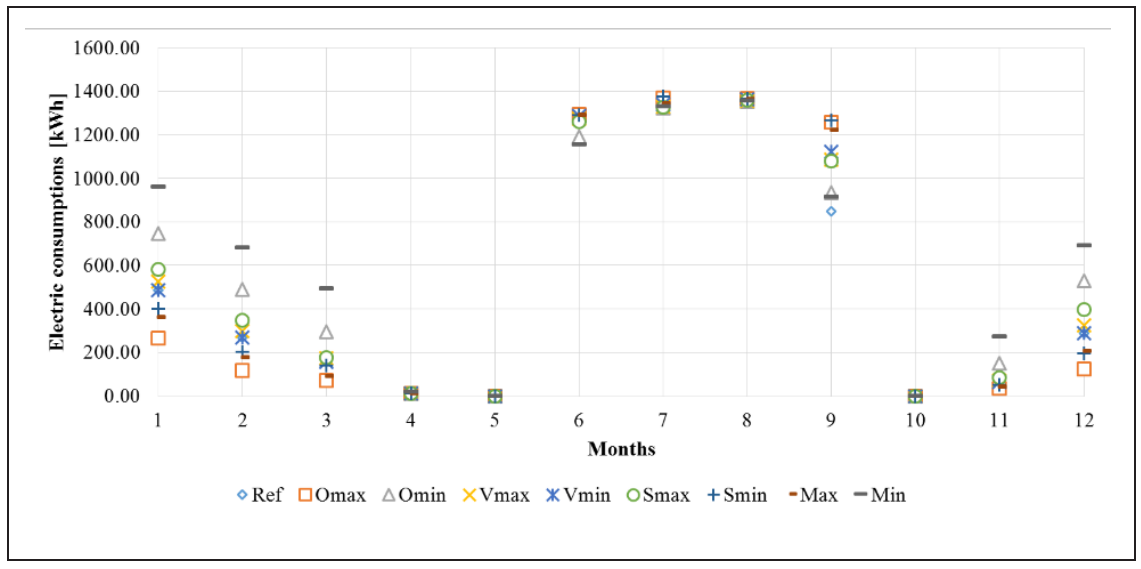

Fig. 12. Electric energy consumptions in the analysed cases for the different months of the year $[\mathrm{kWh}]$.

The annual results are also interesting in order to evaluate the variation of annual electricity consumptions and the coverage by renewable sources (Fig. 13).

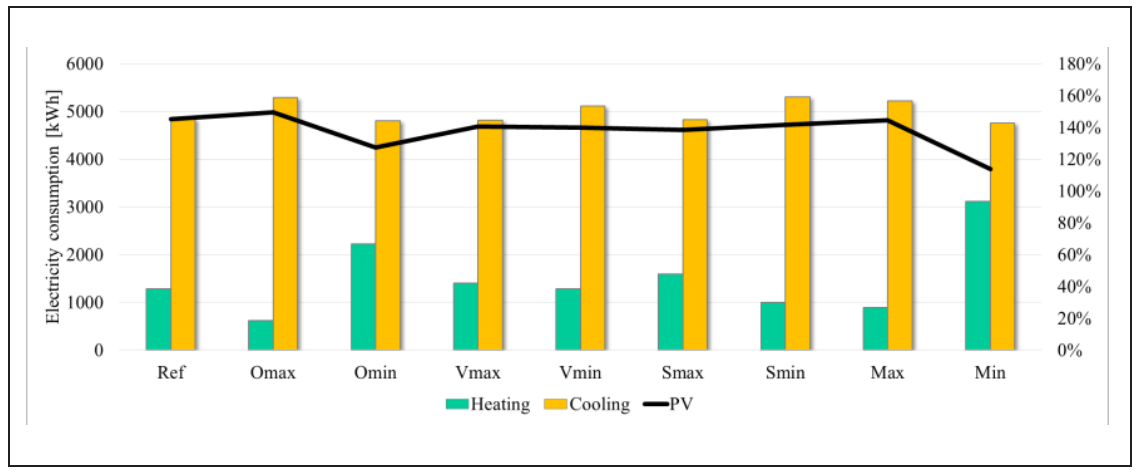

Fig. 13. Annual Electric energy consumptions $[\mathrm{kWh}]$ and percentage of coverage by photovoltaic renewable production in the analysed cases.

The best configurations in winter are the Omax and Max with a decrease of electric energy consumptions of $51 \%$ and $30 \%$ respect to the Ref case. The others cases reach a variation of $+74 \%$ for Omin, $+10 \%$ for Vmin, $+25 \%$ for Smax and $-22 \%$ for Smin.

The Vmin case does not show a notable percentage variation related to the Ref_case, while the Min case has an amount 2.4 times greater than the Ref case. This influences the percentage of the coverage by photovoltaic production rate that is the lowest of the analysed configurations. In fact, the winter season is critical because of the natural variability of solar source in terms of photovoltaic producibility and the monthly surplus energy production is absent in January and December for Omin and Min cases (Fig. 14). The PV coverage is in fact $94 \%$ (Jan) and 96\% (Dec) for the Omin case and 82\% (Jan) and 87\% (Dec) for the Min case. 


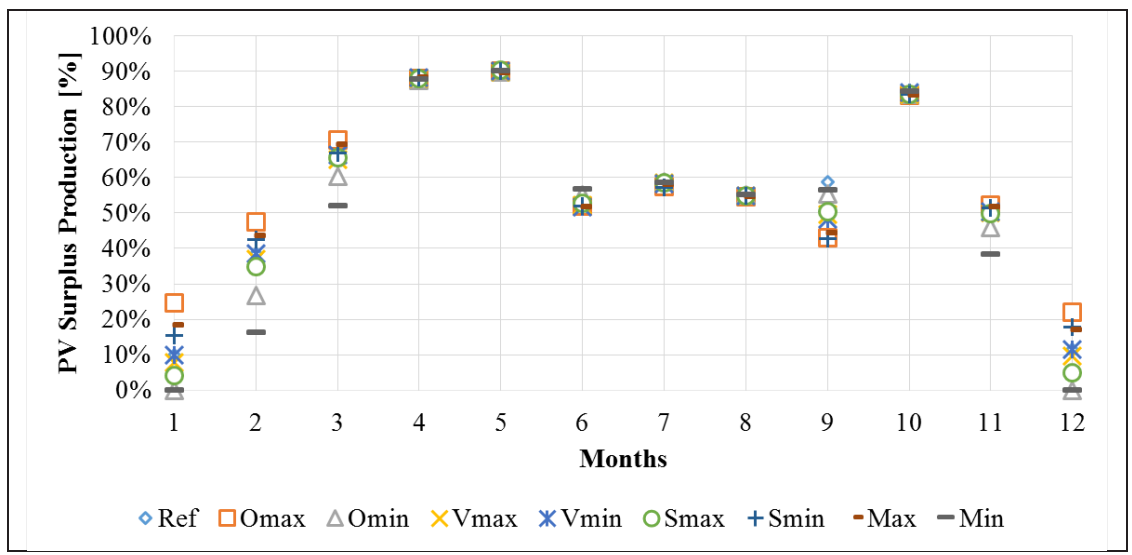

Fig. 14. Monthly surplus PV production [\%] in the analysed cases.

For summer, the annual variations of the electricity consumptions are limited: the worst configurations are Omax $(+9 \%)$ and Smin $(+10 \%)$, followed by the Max case $(+8 \%)$. The Vmin registers a rise of $6 \%$, while the best performances are achieved by Min case $(-2 \%)$ and Omin (-1\%).

\section{Conclusions}

The work demonstrated that the objective to achieve a Zero Energy Building is a challenge for engineers and architects especially in a preliminary phase design. It requires not only a great attention to the project of the building, but also the use of advanced tools in order to evaluate its high performance, considering the variability of climatic conditions and all the detailed aspects related to the dynamic simulations.

The main parameters to be evaluated, in fact, are multiple and influence the performance of building extremely. For this reason, the reference case study here presented has been thought appositely for ensuring the Zero Energy goal.

Even if the main design regards envelope components and their thermal characteristics, orientation, distribution layout and the choice of the adapt plant systems to achieve the building energy requirement for air conditioning and DHW production in residential buildings, many aspects are often neglected, such as the use of reliable climatic data and proper using profiles.

The study has put in evidence the importance of the choice of reliable weather files that determines a difficulty in the assessment of energy consumption and consequently in meeting the demand with renewable energy production. The EP case, in fact, shows lower PV production especially in critical winter months (reaching about the $66 \%$ and $71 \%$ of the total electric energy need in January and December). This could seriously compromise the achievement of Zero Energy target, although the EP case is a positive building considering the annual balance.

Moreover, the work demonstrated the variability of the results according to the influence of ventilation, shading and occupancy profiles, that are often neglected in the design phase. Among all these aspects, the occupancy plays a fundamental role in the analysed case. In fact, the contribution of this aspect is greater in a high-performance building, where the building envelope is well projected and high insulated, and it determines that the other parameters influence rises. Shading systems and ventilation functioning affected the model in less relevant way with respect to the occupancy. Thus, the total differences of electric energy need obtained varying one functioning profile at a time range from $-51 \%$ (Omax; 623 
$\mathrm{kWh})$ to $+74 \%(\mathrm{Omin} ; 2224 \mathrm{kWh}$ ) for heating and from $-1 \%$ (Omin; $4804 \mathrm{kWh}$ ) to $10 \%$ (Smin; $5300 \mathrm{kWh})$ for cooling, respect to the Ref_case $(1280 \mathrm{kWh}$ for heating; $4832 \mathrm{kWh}$ for cooling).

Finally, the combination of minimum and maximum profiles determine a non-linear variation related to the single cases and, in particular, the Min case has the lowest percentage coverage by renewable sources energy production, due to the increase in energy need especially in the winter season. The total range of electric energy variation between the two configurations is from -2\% (Min; $4758 \mathrm{kWh}$ ) to $8 \%$ (Max; $5217 \mathrm{kWh}$ ) for cooling, while for heating the Max case requires $-30 \%$ of electric energy $(892 \mathrm{kWh})$ and the Min case requires 2.4 times more energy $(3116 \mathrm{kWh})$ than the Ref_case. This is due to the fact that, being the envelope highly insulated, the internal gains effects become relevant in the heating season, so much that, if the occupancy is maximum, the electric energy need decreases, whilst if it is minimum, the need increases and doubles. This implies that the occupancy (which is a parameter that varies greatly depending on the inhabitants' behaviour) is the more relevant in the energy balance, if compared with the ventilation and shading with dynamic solar control schedule.

These results demonstrate how is great the variability and the uncertainties in the assessment of a high-performance building.

The criticisms evidenced in the study could be overcome with a detailed approach to building design and simulation, hypothesizing the most accurate and realistic profiles of occupancy and shading and ventilation functioning. Moreover, it is important to achieve the awareness of results variability through a sensibility analysis in order to consider the range in which the energy performance falls and to take into account some design advanced tools (such as the choice of dynamic control systems for shading and ventilation that limit the influence of users and occupants behavior).

Regarding the climatic weather data reliability, the problem is more complicated and it depends on the aim of the analysis. For a specific energy audit in existing buildings, it would be needed to adopt monitored data derived from weather station near the selected location or to act an in-situ measurement campaign, depending strictly on the place. However, in general, for a design preliminary stage, it is necessary to consider the most accurate and recent climate data, provided by reliable and certified sources, considering a reference year created for the best match with the trend of the last years.

Future development would include further studies about the influence of electrical appliances and lighting in the total balance of a zero energy residential building. The actual standard does not consider them for residential buildings, but this aspect contributes surely on electric energy consumptions and could be critical for achieving the total coverage by renewable sources.

In conclusion, it can be affirmed surely that it is necessary to consider each parameter according to the actual use of the building, anticipating the occupants needs and every functioning profile that could occur in the real life in order to assess the energy performance of a $\mathrm{ZEB}$ in the most accurate and realistic way.

\section{Funding}

This research was funded by Programme Agreement with the Italian Ministry of Economic Development, under the Electric System Research. 


\section{References}

1. Rapporto Annuale Efficienza Energetica 2020 / Annual Report on Energy Efficiency 2020. (https://www.efficienzaenergetica.enea.it/pubblicazioni/raeerapporto-annuale-sull-efficienza-energetica/rapporto-annuale-sull-efficienzaenergetica-2021.html)

2. https://www.iea.org/reports/tracking-buildings-2020 (last access: 12/06/2021)

3. Directive 2010/31/EU of the European Parliament and of the council of 19 May 2010 on the energy performance of buildings (recast). Off J Eur Union 2010; L 153:13e35. Available online at: http://eur-lex.europa.eu/legal-

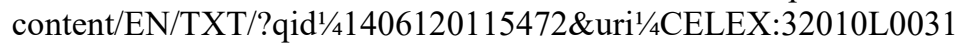

4. S. Di Turi, I. Falcone, I. Nardi, L. Ronchetti, N. Calabrese. Analisi energetica di edifici in direzione Zero Energy Buildings in Italia: stato dell'arte (Energy analysis of buildings towards Zero Energy Buildings in Italy: state of the art). Report RdS/PTR2019/033.

5. Towards nearly zero energy buildings Definition of common principles under the EPBD Final report https://ec.europa.eu/energy/sites/ener/files/documents/nzeb_full_report.pdf (last access: 12/06/2021)]

6. D. D'Agostino, L. Mazzarella. What is a Nearly zero energy building? Overview, implementation and comparison of definitions. J Build Eng 21, 200-212 (2019)

7. G. Lobaccaro, A. H. Wiberg, G. Ceci, M. Manni, N. Lolli, U. Berardi. Parametric design to minimize the embodied GHG emissions in a ZEB. Energ Build 167, 106$123(2018)$

8. P. Torcellini, S. Pless, M. Deru, D. Crawley. Zero Energy Buildings: A Critical Look at the Definition. 2006 ACEEE Summer Study on Energy Efficiency in Buildings

9. D. Mazzeo, N. Matera, C. Cornaro, G. Oliveti, P. Romagnoni, L. De Santoli. EnergyPlus, IDA ICE and TRNSYS predictive simulation accuracy for building thermal behaviour evaluation by using an experimental campaign in solar test boxes with and without a PCM module. Energ Build 212, 109812 (2020)

10. R.S. Adhikari, N. Aste, C. Del Pero, M. Manfren. Net Zero Energy Buildings: Expense or Investment? Energy Proced 14, 1331-1336 (2012)

11. Y. Lu, S. Wang, K. Shan. Design optimization and optimal control of gridconnectedand standalone nearly/net zero energy buildings. Appl Energ 155, 463477 (2015)

12. V.Shabunko, C.M.Lim, S.Mathew. EnergyPlus models for the benchmarking of residential buildings in Brunei Darussalam. Energ Build 169, 507-516 (2018)

13. F. Ascione, N. Bianco, T. Iovane, M. Mastellone, G.M. Mauro. Conceptualization, development and validation of EMAR: A user-friendly tool for accurate energy simulations of residential buildings via few numerical inputs. J Build Eng 44, 102647 (2021).

14. Decreto Ministeriale 26.6.2015. Applicazione delle metodologie di calcolo delle prestazioni energetiche e definizione delle precisazioni e dei requisiti minimi degli edifici (Ministerial Decree 26.6.2015. Application of the methodologies for calculating energy performance and definition of the details and minimum requirements of buildings). 